\title{
Sensitivity to penicillin of gonococci in different racial groups
}

\author{
P RODIN,* A D SETH,† D M KING,* AND A E WILKINSON† \\ From the *Whitechapel Clinic and the +Venereal Diseases Reference Laboratory (PHLS), the London \\ Hospital, London
}

SUMMARY The distribution of the sensitivity to penicillin of gonococci isolated from 631 men and 290 women was analysed in relation to the racial origin of the patients and the type of source contact alleged by the men. No difference in the sensitivity patterns was found between strains from white patients from the United Kingdom and those from immigrants from the Caribbean area. Asian men harboured significantly more insensitive strains than men of other racial groups. Men of Caribbean stock who had been born in this country had significantly more infections due to fully sensitive strains. The reasons for these variations are not known, but one contributory factor may be differences within the racial groups in the proportions of infections contracted from prostitutes.

\section{Introduction}

In a nationwide study of gonorrhoea carried out in the United States between 1972 and 1975 Thornsberry et $a l^{1}$ found a significantly higher proportion of strains which were relatively insensitive to penicillin-with minimum inhibitory concentrations (MICs) of penicillin between 0.125 and $0.25 \mu \mathrm{g} / \mathrm{ml}$-among black patients than in white men and women, although the proportion of more resistant isolates (MIC $\geqslant 0.5 \mu \mathrm{g} / \mathrm{ml}$ ) was similar in both races and sexes. Reasons suggested to account for this difference were possible selective factors, such as the tendency for relatively resistant strains to produce symptomatic infections and the degree of motivation in different racial groups to seek treatment, variations in the provision of treatment facilities in different communities, and variations in the distribution of sensitivity of gonococci to antibiotics in different geographical areas. Silver and Darling, ${ }^{2}$ working at Bolton in the UK, found that gonococcal strains isolated from a small group of coloured immigrants were significantly less sensitive to penicillin than those from non-immigrants in the same area.

In view of these reports a retrospective study was carried out to see whether there were any differences in the distribution of sensitivity of gonococci to

Address for reprints: Dr P Rodin, Whitechapel Clinic, London Hospital, London E1 1BB

Received for publication 10 December 1979 penicillin among patients of different racial groups who had attended a venereal disease clinic in London.

\section{Materials and methods}

Strains of Neisseria gonorrhoeae isolated before treatment from 631 men and 290 women who attended the Whitechapel Clinic of the London Hospital between 1976 and 1978 were tested for susceptibility to penicillin by a plate dilution method. ${ }^{3}$ The identity of all the isolates was confirmed by an oxidase test and the production of acid from glucose but not from maltose, lactose, or saccharose. The patient's race and country of birth were noted as well as, in the men, the type of sexual contact from whom the infection was thought to have been acquired. The number of patients studied represented about $20 \%$ of the total number of patients with gonorrhoea who attended the clinic during the period reviewed. All isolates from patients attending during certain consecutive months in each of the years 1976, 1977, and 1978 were tested, but there was no other selection.

The $\chi^{2}$ test was used to examine differences in the distribution of the sensitivity of strains within racial and other groups.

\section{Results}

STRAIN SENSITIVITIES

These are summarised in tables I and II. Gonococcal strains with an MIC of $\leqslant 0.004-0.015 \mu \mathrm{g} / \mathrm{ml}$ were 
TABLE I Sensitivity of gonococci to penicillin in racial groups (1976-78)

\begin{tabular}{|c|c|c|c|c|c|c|c|}
\hline \multirow[b]{3}{*}{ Racial group } & \multirow[b]{3}{*}{ No } & \multicolumn{6}{|c|}{$M I C(\mu g / m l)$} \\
\hline & & \multicolumn{2}{|c|}{$\leqslant 0 \cdot 004-0.015$} & \multicolumn{2}{|c|}{$0.03-0.06$} & \multicolumn{2}{|c|}{$0.125-\geqslant 0.5$} \\
\hline & & $\overline{N o}$ & $\%$ & $\overline{N o}$ & $\%$ & No & $\%$ \\
\hline $\begin{array}{l}\text { Men: } \\
\text { UK and Eire } \\
\text { UK coloured } \\
\text { Caribbean negro } \\
\text { African negro } \\
\text { Asian* } \\
\text { Miscellaneous } \\
\text { Total }\end{array}$ & $\begin{array}{r}227 \\
40 \\
208 \\
32 \\
55 \\
69 \\
631\end{array}$ & $\begin{array}{r}134 \\
33 \\
125 \\
13 \\
13 \\
38 \\
356\end{array}$ & $\begin{array}{l}59 \cdot 0 \\
82 \cdot 5 \\
60 \cdot 1 \\
40 \cdot 6 \\
23 \cdot 6 \\
55 \cdot 1 \\
56 \cdot 4\end{array}$ & $\begin{array}{r}49 \\
4 \\
43 \\
10 \\
26 \\
14 \\
146\end{array}$ & $\begin{array}{l}21 \cdot 6 \\
10 \cdot 0 \\
20 \cdot 7 \\
31 \cdot 2 \\
47 \cdot 3 \\
20 \cdot 3 \\
23 \cdot 1\end{array}$ & $\begin{array}{r}44 \\
3 \\
40 \\
9 \\
16 \\
17 \\
129\end{array}$ & $\begin{array}{r}19 \cdot 4 \\
7 \cdot 5 \\
19 \cdot 3 \\
28 \cdot 1 \\
29 \cdot 1 \\
24 \cdot 6 \\
20 \cdot 4\end{array}$ \\
\hline $\begin{array}{l}\text { Women: } \\
\text { UK and Eire } \\
\text { UK coloured } \\
\text { Caribbean negro } \\
\text { African negro } \\
\text { Asian* } \\
\text { Miscellaneous } \\
\text { Total }\end{array}$ & $\begin{array}{r}202 \\
20 \\
53 \\
4 \\
1 \\
10 \\
290\end{array}$ & $\begin{array}{r}122 \\
14 \\
37 \\
2 \\
0 \\
6 \\
181\end{array}$ & $\begin{array}{l}60 \cdot 4 \\
70 \cdot 0 \\
69 \cdot 8\end{array}$ & $\begin{array}{r}44 \\
3 \\
9 \\
2 \\
0 \\
1 \\
59\end{array}$ & $\begin{array}{l}21 \cdot 8 \\
15 \cdot 0 \\
17 \cdot 0\end{array}$ & $\begin{array}{r}36 \\
3 \\
7 \\
0 \\
1 \\
3 \\
50\end{array}$ & $\begin{array}{l}17 \cdot 8 \\
15 \cdot 0 \\
13 \cdot 2\end{array}$ \\
\hline
\end{tabular}

*Indian, Bangladeshi, and Pakistani patients

TABLE II Distribution of sensitivity to penicillin in strains in men from different sources of infection

\begin{tabular}{|c|c|c|c|c|c|c|c|c|c|c|c|c|}
\hline \multirow[b]{3}{*}{$M I C(\mu g / m l)$} & & & \multicolumn{10}{|c|}{ Source of infection } \\
\hline & \multicolumn{2}{|c|}{ Strains } & \multicolumn{2}{|c|}{ Prostitute } & \multicolumn{2}{|c|}{ Casual } & \multicolumn{2}{|c|}{ Friend } & \multicolumn{2}{|c|}{ Marital } & \multicolumn{2}{|c|}{ Homosexual } \\
\hline & No & $\%$ & No & $\%$ & No & $\%$ & No & $\%$ & No & $\%$ & No & $\%$ \\
\hline $\begin{array}{l}\leqslant 0 \cdot 004-0 \cdot 015 \\
0 \cdot 03-0 \cdot 06 \\
0 \cdot 125-\geqslant 0 \cdot 5 \\
\text { Total }\end{array}$ & $\begin{array}{l}356 \\
146 \\
129 \\
631\end{array}$ & $\begin{array}{l}56 \cdot 4 \\
23 \cdot 1 \\
20 \cdot 4 \\
100\end{array}$ & $\begin{array}{l}27 \\
14 \\
15 \\
56\end{array}$ & $\begin{array}{l}48 \cdot 2 \\
25 \cdot 0 \\
26 \cdot 8 \\
100\end{array}$ & $\begin{array}{r}234 \\
105 \\
86 \\
425\end{array}$ & $\begin{array}{l}55 \cdot 1 \\
24 \cdot 7 \\
20 \cdot 2 \\
100\end{array}$ & $\begin{array}{r}73 \\
22 \\
20 \\
115\end{array}$ & $\begin{array}{l}63 \cdot 5 \\
19 \cdot 1 \\
17 \cdot 4 \\
100\end{array}$ & $\begin{array}{r}12 \\
3 \\
0 \\
15\end{array}$ & $\begin{array}{l}80 \cdot 0 \\
20 \cdot 0 \\
100\end{array}$ & $\begin{array}{r}10 \\
2 \\
8 \\
20\end{array}$ & $\begin{array}{r}50 \cdot 0 \\
10 \cdot 0 \\
40 \cdot 0 \\
100\end{array}$ \\
\hline
\end{tabular}

classed as fully sensitive, those with an MIC of $0.03-0.06 \mu \mathrm{g} / \mathrm{ml}$ as of intermediate sensitivity, and those with an MIC of $\geqslant 0.125 \mu \mathrm{g} / \mathrm{ml}$ as being relatively insensitive. There were no significant differences between the distribution of these three groups of strains between male or female white patients from the United Kingdom and Eire and those from the Caribbean. However, the male UK coloured patients (those of Caribbean stock who had been born and had grown up in the UK) had significantly more fully sensitive strains than white UK men $\left(\chi_{1}^{2}=8 \cdot 0, P=<0.01\right)$. No difference in the frequency of fully sensitive strains was found between the male and female UK coloured patients $\left(\chi_{1}^{2}=1 \cdot 28, \quad P=<0 \cdot 3>0 \cdot 2\right)$. Asian male patients (from India, Bangladesh, and Pakistan) were infected with significantly more intermediate and relatively insensitive strains than the other racial groups $\left(\chi_{2}^{2}=28.9, P=<0.01\right)$. These strains were also found more frequently in the male African negroes, but when compared with the remainder of the male patients the difference was not significant at the 0.05 level.

\section{SOURCES OF INFECTION}

The sources of infection of the male patients are shown in table III. Excluding homosexually acquired infections, the Asian patients gave prostitutes as their contacts more often than the other groups $\left(\chi_{1}^{2}=28 \cdot 8, P=<0 \cdot 01\right)$. Caribbean men and male UK coloured patients had relatively fewer infections from prostitutes than the male group as a whole $\left(\chi_{1}^{2}=5.5, P=0.02\right.$; and $\chi_{1}^{2}=4 \cdot 3, P=<0.05>0.02$ respectively). Although there were differences in the distribution of the three sensitivity groups in the men infected by different types of female source contacts (table II), these were not significant $\left(\chi_{6}^{2}=9 \cdot 3\right.$, $P=<0.3>0.2$ ). There was a tendency for the less sensitive strains to be found most often in the contacts of prostitutes, then in declining order, casual contacts, friends, and wives; this may perhaps reflect a gradient of promiscuity within these female groups.

\section{Discussion}

In contrast to the findings in the United States, no 
TABLE III Sources of infection in men

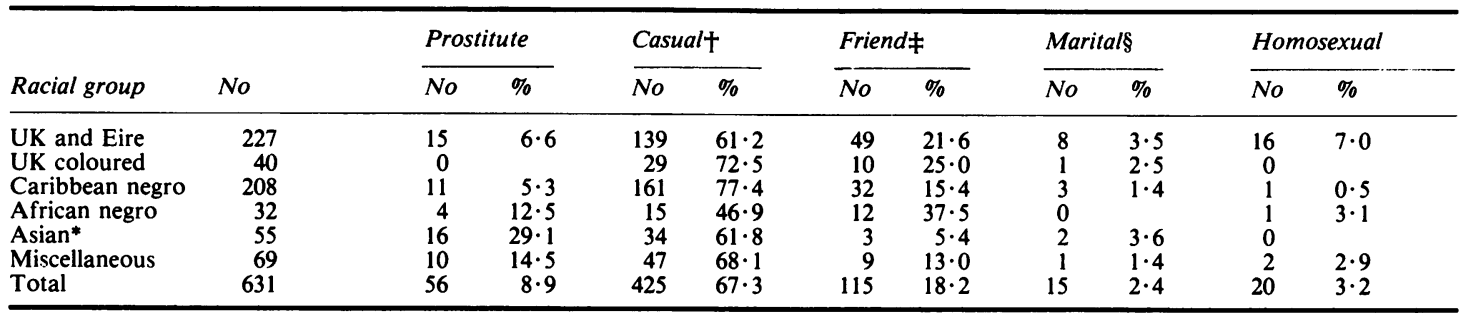

*Indian, Bangladeshi, and Pakistani patients

tRelationship lasting less than one month

fRelationship for at least one month

§Including common law wife

difference was found in the distribution of sensitivity to penicillin of gonococci recovered from UK white patients and negro immigrants from the Caribbean area. Asian men however harboured significantly more strains of reduced sensitivity. It seems likely that these findings are mainly the result of differences in social behaviour. It was at first thought that the frequency with which prostitutes were the source of infection might provide an explanation, but this was not born out when the sensitivity patterns were related to the different types of sexual contact, although there was some suggestion that it might be a contributory factor. Asian patients sometimes seek treatment from local general practitioners and it is possible that a process of antibiotic selection might have operated so that those with less sensitive strains would eventually reach the clinic when the initial treatment had failed. However, only one of the Asian men admitted having taken antibiotics shortly before his attendance. We cannot explain why UK-born coloured men had significantly more of the highly sensitive strains, but it may be relevant that none admitted to a prostitute being his source of infection.

We wish to thank the World Health Organisation for financial support.

\section{References}

1. Thornsberry C, Jaffe HW, Reynolds GH, Zaidi AA, Wiesner PJ. Patient variables associated with penicillin resistance in Neisseria gonorrhoeae. Antimicrob Agents Chemother 1978; 14:327-30.

2. Silver PS, Darling WM. Penicillin insensitive gonococci in the Bolton area. Preponderance in young women and immigrants. Br J Vener Dis 1971;47:367-72.

3. Seth AD, Kolator B, Wilkinson AE. Sensitivity of Neisseria gonorrhoeae to antibiotics in London (1976-1978). Br J Vener Dis 1979; 55: 325-8. 